\title{
Energy Modelling on Taper Tool Geometry of Aluminium Alloys using C Program
}

\author{
J. Jayapriya ${ }^{1 *}$, D. Muruganandam², S. Gopalakrishnan² and S. Briolin Nayagam ${ }^{3}$ \\ 'Department of Mathematics, Sathyabama University, Chennai - 600119, Tamil Nadu, India; \\ Priyanandam_1975@rediffmail.com \\ ${ }^{2}$ Department of Production Engineering, SriSairam Engineering College, Chennai - 600 044, Tamil Nadu, India; \\ murudurai@gmail.com,gopalakrishnan11061994@gmail.com \\ ${ }^{3}$ Department of Computer Science, Jeppiaar Institute of Technology, Sriperumbudur, \\ Kanchipuram -631604, Tamil Nadu, India; sbriolin3@gmail.com
}

\begin{abstract}
Friction stir welding is solid state joining process where the energy efficiency is dependant on the selection of tool geometry. The objective of this work is to reduce time consumption in calculating tool geometric parameters using $\mathrm{C}$ program. As the tool being of different geometry in concern with different complex operation, the energy generated and the temperature distribution which influenced by efficient energy is to be calculated. The calculation is performed based on the machining different work pieces by adjusting tool parameters of aluminium alloys such as Al6061-T6, Al22024-T6, Al7075-T6. Six different cases had been generated in our work for each Aluminium alloy where different RPM (Rotation Per Minute) such as 200, 400,600, 800,1000,1200 was maintained and compared to translational speed and applied normal force. The Energy and Maximum Temperature obtained using Taper Model and the Cylindrical model is compared based on the data processed during the machining. The proposed energy model equation is helpful in computing these data. Manual calculation in these equation may lead to large consumption. Thus the different tool parametric value can be easily generated by coding these equation in C program and feeding necessary input parameters from users. Thereby it generates the different values at faster rate. From this experiment, it is found that abrupt changes in the process may lead influence the efficiency of welding the material and may affect it. Larger data regarding the tool parameter can be processed easily at less time using C. Different tools have different parametric changes and thereby having knowledge over its parameters may not affect the work pieces. C program help to generate these data. Further improvement can be made by doing same study over different other tools and by coding these different values calculated maybe helpful in tool selection. The study can also be made over similar other welding processes too and also help in prevention of damage of different work pieces.
\end{abstract}

Keywords: C-Programming, Energy Model, Friction Stir Welding, Taper Tool, Temperature Model

\section{Introduction}

Frictional stir welding is process joining similar and dissimilar metals using non consumable tools. The main parameters involved in calculating the energy and temperature models of taper tool are rotational speed, transverse speed in rpm and axial load in $\mathrm{kN}$. The source for joining the two metals is formation of heat which may be from the chemical or electrical energy during the process. Thus the chemical energy mechanism and atomic energy liberation is being neglected from the numerical equation formulations ${ }^{1}$. Formulated the three-dimensional visco-plastic modeling of the friction stir-welding process ${ }^{2}$. Worked on the Numerical and experimental study of the heat transfer process in friction stir welding and formulated a mathematical model to describe the detailed three-dimensional transient heat transfer process in Friction Stir Welding (FSW). Here the heat input from the tool shoulder is modelled as a frictional heat and the heat from the tool pin is modelled as a uniform

${ }^{*}$ Author for correspondence 
volumetric heat generated by the plastic deformation near the pin formulated ${ }^{3}$. Two-dimensional friction stir welding process model based on fluid mechanics ${ }^{4}$. Formulated 3-Dimensional modelling of flow round a threaded friction stir welding tool profile using CFD (Computational Fluid Dynamics) code, formulated the Mechanical and thermal modelling of Friction Stir Welding 5 . Experimented CFD modelling of friction stir welding of thick plate 7449 aluminium alloy for aerospace applications to produce high strength, defect free welds that do not break the tool' ${ }^{6}$. Developed a thermal model of friction stir welding in aluminum alloys which utilizes a new slip factor based on the energy per unit length of weld ${ }^{7}$. The slip factor is derived from an empirical, linear relationship observed between the ratio of the maximum welding temperature to the solidus temperature and the welding energy ${ }^{8}$. Formulated about the Numerical Simulation of Friction Stir Welding on Aluminum Alloy 2024-T351 Plates using finite difference method - explicit scheme with adaptive grid, considering influence of temperature on material's conductivity, contact conditions between welding tool and parent material, material flow around welding tool etc., discussed about the Role of Tool Pin Profile in structure and property correlation of Friction Stir Welding of AA2014 material' ${ }^{9}$. Formulated the heat generation numerical equations for cylindrical taper tool pin profile of FSW reducing the time consumption in experimental effort for the development of welding parameters, tool design ${ }^{10}$. Friction stir welding uses a rotating tool pin profile for welding of two metal plates. Here in this model we use a taper pin profile having different ratio of HAZ, TMAZ from other pin profiles. The diagrammatic representation of FSW is shown in Figure 1.

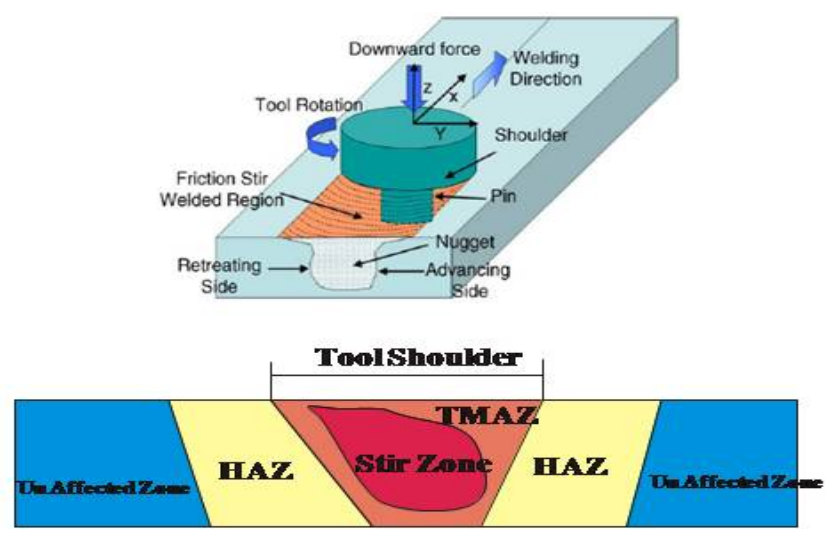

Figure 1. The schematic representation of Friction Stir Welding.

\section{Proposed Energy Model}

From the various previous literature studies it is stated to neglecting the values of the heat generation due to plastic deformation within work piece and the friction of the pin of the material and the heat generation due to friction of the pin shoulder on the work piece surface is said to be considered in the formulation of numerical equation of the taper pin profile of FSW tool ${ }^{11}$. From the studies and it is found to be the heat generated due to plastic flow ${ }^{5}$. The proposed energy model of the taper tool pin profile ID shown in below Figure $2^{7}$.

From the previous work it is derived to be the taper toll pin liberating the energy as the following formulation $^{12}$. The maximum energy thus liberated during the FSW (Friction Stir Welding) process using taper pin profile is as follows,

$E_{f}=\frac{2}{3} \mu F\left[\frac{\left(r_{s}\right)^{3}}{\left(r_{p}\right)_{2}^{2}}-\left(r_{p}\right)_{2}+\frac{\left(\left(r_{p}\right)_{1}\right)^{3}}{\left(r_{p}\right)_{2}^{2}}+\frac{\left(\left(r_{p}\right)_{1}+\left(r_{p}\right)_{2}\right)}{\left(r_{p}\right)_{2}} h\right] \frac{\omega}{v_{0}}$

By using the energy liberation value $E_{f}$ and considering previous work relationship the value of Total energy $E$ is being equated as follows:

Where the $\mu=$ coefficient of friction, $r_{s}=$ radius of the shoulder pin of FSW Taper tool, $(\mathrm{rp})_{1}=$ radius of the smaller tool pin of Taper FSW tool, $(\mathrm{rp})_{2}=$ radius of the larger tool pin of Taper FSW tool, F = Axial load, $\omega=$ Rotational speed of the Taper FSW tool, $\mathrm{v}_{\mathrm{o}}=$ Transverse speed of the Taper FSW tool. By using the energy liberation value $E_{f}$ and considering previous work relationship the value of Total energy $\mathrm{E}$ is being equated as follows:

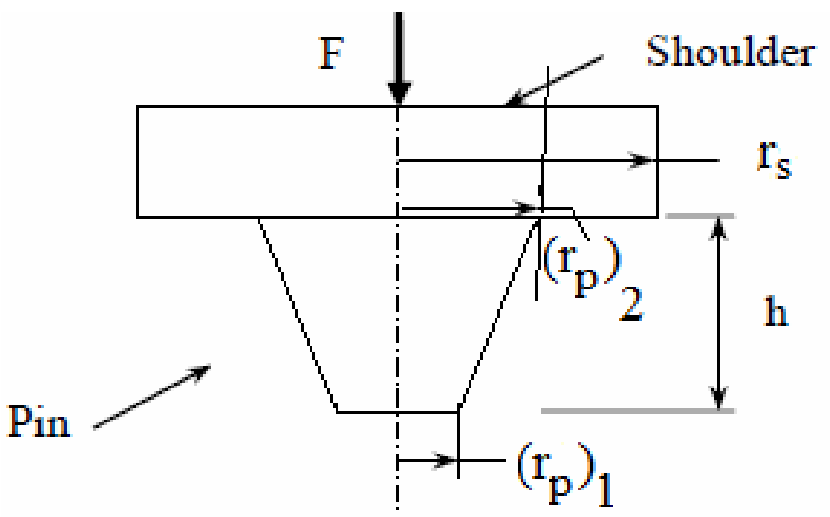

Figure 2. The energy model of taper tool pin profile. 


$$
\begin{gathered}
E=E_{f}+s E_{p} \\
E_{f}=\frac{2}{3} \mu F\left[\frac{\left(r_{s}\right)^{3}}{\left(r_{p}\right)_{2}^{2}}-\left(r_{p}\right)_{2}+\frac{\left(\left(r_{p}\right)_{1}\right)^{3}}{\left(r_{p}\right)_{2}^{2}}+\frac{\left(\left(r_{p}\right)_{1}+\left(r_{p}\right)_{2}\right)}{\left(r_{p}\right)_{2}} h\right] \frac{\omega}{v_{0}}+s \sigma_{e} s_{e} b l h
\end{gathered}
$$

Thus the value of the efficient energy $\mathrm{E}_{\text {eff }}$ can be known from following formulation where it takes into account the value of the height of the FSW tool pin and the thickness of the tool pin.

$$
E_{\text {eff }}=\frac{h}{t} E=\beta E
$$

Where $\beta$ be the coefficient of the transfer efficiency, $\mathrm{h}=$ height of the FSW taper tool, $\mathrm{t}=$ length of FSW taper tool. The following are the Tables 1, 2, 3 that comparatively reviews and describe about various combination of joining different materials and their different welding parameters.

The equation for the deriving temperature modeled of FSW taper tool pin. The equation is shown below

$$
\frac{T_{\max }}{T_{s}}=1.56 * 10^{-4 *} E_{\text {eff }}+0.54
$$

where $T_{\max }$ is the maximum temperature and the $T_{\mathrm{s}}=$ solidus temperature.

Tables 1, 2, 3 describe about the various parameter such as density, thickness, heat flow, tool geometry, Welding Rotational and Translational speeds and the applied normal force, Energy and Maximum Temperature obtained using Taper Model and the Cylindrical model etc. It is found that the energy calculated in the numerical equation

\begin{tabular}{|c|c|c|c|c|}
\hline \multicolumn{2}{|c|}{ Aluminium Alloy } & 6061-T6 & 2024-T6 & 7075-T6 \\
\hline \multicolumn{2}{|c|}{ Ref. } & L1 & L2 & L3 \\
\hline \multicolumn{2}{|c|}{$\mathrm{t}(\mathrm{mm})$} & 6 & 6 & 6 \\
\hline \multicolumn{2}{|c|}{$\rho\left(\mathrm{kg} / \mathrm{m}^{3}\right)$} & 2700 & 2780 & 2810 \\
\hline \multicolumn{2}{|c|}{$\mathrm{C}_{\mathrm{p}}(\mathrm{J} / \mathrm{KgK})$} & 896 & 875 & 960 \\
\hline \multicolumn{2}{|c|}{$\mathrm{K}(\mathrm{W} / \mathrm{mK})$} & 167 & 177 & 130 \\
\hline \multicolumn{2}{|c|}{$a\left({ }^{*} 10^{-6} \mathrm{~cm} / \mathrm{cm} / \mathrm{C}\right)$} & 23.4 & 22.8 & 23.2 \\
\hline \multicolumn{2}{|c|}{$\mathrm{T}_{\mathrm{s}}(\mathrm{K})$} & 855 & 910 & 748 \\
\hline \multirow{3}{*}{$\begin{array}{c}\text { Tool } \\
\text { Geometry }\end{array}$} & $\mathrm{r}_{\mathrm{i}}(\mathrm{mm})$ & 12.0 & 12.0 & 12.0 \\
\hline & $\mathrm{r}_{\mathrm{o}}(\mathrm{mm})$ & 9.5 & 9.5 & 9.5 \\
\hline & $\mathrm{h}(\mathrm{mm})$ & 6.0 & 6.0 & 6.0 \\
\hline
\end{tabular}
make influence in formulating the temperature model.

Table 1. Material characteristics and tool geometry of the aluminium alloys used
Table 2. Welding rotational and translational speeds and the applied normal force

\begin{tabular}{|c|c|c|c|c|}
\hline Alloy & Case & R.P.M & $\mathbf{v}_{\mathbf{0}}(\mathrm{mm} / \mathbf{s})$ & $\mathrm{F}(\mathrm{kN})$ \\
\hline AA 6061 - T6 & 1 & 200 & 1.5 & 10 \\
\cline { 2 - 5 } & 2 & 400 & 1.5 & 10 \\
\cline { 2 - 5 } & 3 & 600 & 1.5 & 10 \\
\cline { 2 - 5 } & 4 & 800 & 1.5 & 10 \\
\cline { 2 - 5 } & 5 & 1000 & 1.5 & 10 \\
\cline { 2 - 5 } & 6 & 1200 & 1.5 & 10 \\
\hline AA 2024 - T6 & 7 & 200 & 1.5 & 10 \\
\cline { 2 - 5 } & 8 & 400 & 1.5 & 10 \\
\cline { 2 - 5 } & 9 & 600 & 1.5 & 10 \\
\cline { 2 - 5 } & 10 & 800 & 1.5 & 10 \\
\cline { 2 - 5 } & 11 & 1000 & 1.5 & 10 \\
\cline { 2 - 5 } & 12 & 1200 & 1.5 & 10 \\
\hline AA 7075 - T6 & 13 & 200 & 1.5 & 10 \\
\cline { 2 - 5 } & 14 & 400 & 1.5 & 10 \\
\cline { 2 - 5 } & 15 & 600 & 1.5 & 10 \\
\cline { 2 - 5 } & 16 & 800 & 1.5 & 10 \\
\hline & 17 & 1000 & 1.5 & 10 \\
\cline { 2 - 5 } & 18 & 1200 & 1.5 & 10 \\
\hline
\end{tabular}

Table 3. Energy and maximum temperature obtained using Taper Model and the Cylindrical model

\begin{tabular}{|c|c|c|c|c|}
\hline Case \# & $\begin{array}{c}\mathrm{E}(\mathrm{J} / \mathrm{mm}) \\
\text { cylindrical } \\
\text { model }\end{array}$ & $\begin{array}{c}\mathrm{E}(\mathrm{J} / \mathrm{mm}) \\
\text { Taper } \\
\text { model }\end{array}$ & $\begin{array}{c}\mathrm{T}_{\max } \\
\text { cylindrical } \\
\text { model }\end{array}$ & $\begin{array}{c}\mathrm{T}_{\max } \\
\text { Taper } \\
\text { model }\end{array}$ \\
\hline 1 & 975 & 1574 & 114 & 129 \\
\hline 2 & 1881 & 2467 & 137 & 150 \\
\hline 3 & 2824 & 3703 & 160 & 181 \\
\hline 4 & 3760 & 4932 & 183 & 211 \\
\hline 5 & 4702 & 6168 & 207 & 241 \\
\hline 6 & 5643 & 7401 & 230 & 271 \\
\hline 7 & 988 & 1587 & 121 & 137 \\
\hline 8 & 1883 & 2469 & 145 & 159 \\
\hline 9 & 2826 & 3705 & 170 & 191 \\
\hline 10 & 3772 & 4944 & 195 & 223 \\
\hline 11 & 4716 & 6181 & 220 & 255 \\
\hline 12 & 5659 & 7418 & 244 & 287 \\
\hline 13 & 1019 & 1618 & 90 & 101 \\
\hline 14 & 1894 & 2480 & 107 & 101 \\
\hline 15 & 2865 & 3714 & 125 & 141 \\
\hline 16 & 3778 & 4950 & 143 & 164 \\
\hline 17 & 4718 & 6184 & 161 & 168 \\
\hline 18 & 5659 & 7417 & 179 & 211 \\
\hline
\end{tabular}




\section{Experiment}

The main purpose of this paper is to derive the $\mathrm{C}$ coding for the taper model to reduce the time consumption and problem complexity raised during the calculation of the energy and the temperature model of the FSW friction stir welding Taper tool. The various steps involved in the generation of $\mathrm{C}$ programming are as follows:

- Initialize the variables according to their functions such as into, float etc.

- Read all the variables necessary to be declared in the calculation such as axial load (F), rotational speed (w), transverse speed (v), Shoulder diameter (rs), larger pin diameter (rpl), smaller pin diameter (rps), pin height $(\mathrm{H})$ and solidus temperature(s).

- Generate the local variables (a,b,c,d,e,f,g,h,I,j,k,l,m) for the calculation of the energy and temperature formulations.

- Generate equations.

- Verify the C coding.

- If success generate the results.

\section{C Program for the Taper Model}

\#include $<$ stdio.h $>$

\#include $<$ conio.h $>$

void main()

\{

int F,w,rs,rps,rpl,H,s;

float v,a,b,c,d,e,f,g,h,i,j,k,l,m;

printf(" In Enter the value of Axial load ( $4 \mathrm{kN}$ to $12 \mathrm{kN}$ );

$\operatorname{scanf}($ “\%d",F);

printf(" $\backslash n$ Enter the value of Transverse speed (1.5 to 5

$\mathrm{mm} / \mathrm{min}):$ );

scanf(“\%f”,\&v);

printf(“ $\backslash \mathrm{n}$ Enter the value of Rotational speed (200 rpm

to $1200 \mathrm{rpm}:$ ");

scanf(“\%d",\&w);

printf(" $\mid \mathrm{n}$ Enter the value of Shoulder pin diameter

(10mm to $20 \mathrm{~mm}): ")$;

scanf(“\%d”,\&rs);

printf(“ $I n$ Enter the value of smaller pin diameter $(3 \mathrm{~mm}$ to $6 \mathrm{~mm}): ")$;

scanf(“\%d”, \&rps);

printf(" $\mid \mathrm{n}$ Enter the value of larger pin diameter $(6 \mathrm{~mm}$ to $12 \mathrm{~mm})$;

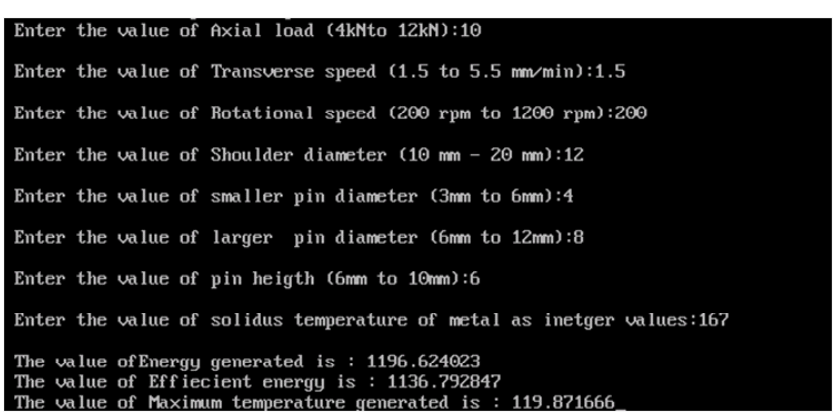

Figure 3. C program output.

scanf(“\%d”, \&rpl);

printf(“'n Enter the value of pin height:");

scanf(“\%d",\&H);

printf(“ $\mid n$ Enter the value of solidus temperature of metal as integer value:");

scanf(“\%d”, \&s);

$\mathrm{a}=0.33^{*} \mathrm{~F}$;

$\mathrm{b}=0.1046^{*} \mathrm{w}$;

$\mathrm{c}=\mathrm{b} / \mathrm{v}$;

$\mathrm{d}=\left(\left(\left(\mathrm{rs}^{*} \mathrm{rs}{ }^{*} \mathrm{rs}\right) /\left(\mathrm{rpl}{ }^{*} \mathrm{rpl}\right)\right)-\mathrm{rpl}\right)$;

$\mathrm{e}=($ rps*rps*rps $) /($ rpl*rpl);

$\mathrm{f}=(\mathrm{rps} / \mathrm{rpl})+1$;

$\mathrm{g}=\mathrm{f} * \mathrm{H}$;

$\mathrm{i}=\mathrm{d}+\mathrm{e}+\mathrm{g}$;

$\mathrm{j}=\mathrm{a}^{*} \mathrm{c}^{*} \mathrm{~h}$;

printf(“'n The value of Energy generated : \% ",j);

$\mathrm{k}=(5.7 / 6)^{*} \mathrm{j}$;

$\mathrm{l}=0.54+((1.564 / 10000) * \mathrm{k})$;

$\mathrm{m}=\mathrm{s}^{*} \mathrm{l}$;

printf(“ $\backslash n$ The value of Efficient energy : \%f”, k);

printf(“ $\backslash n$ The value of Maximum temperature generated:

$\% \mathrm{f}, \mathrm{m})$;

getch();

clrscr();

\}

\section{Results and Discussion}

After the successful execution of the $C$ program, the results obtained is precise and similar to the value generated from the numerical formulation and here the decimal values being consider and the formulation shows more accuracy rather than the to the manual numerical formulations and calculations. The $\mathrm{C}$ program used for the taper model is being shown above generates results is shown in the below Figure. 


\section{Conclusion}

The numerical formulation of the energy and temperature equation of the taper model of various aluminium alloys has described. The model accounts for the heat generated due to the friction between tool and the work piece surfaces. The comparison between the manual numerical formulation is compared with the $\mathrm{C}$ program generated values resulting is close similarity, thereby concluding that $\mathrm{C}$ programming be efficient to generate results.

\section{References}

1. Ulysse P. Three-dimensional modeling of friction stir welding process. International Journal of Machine Tools and Manufacture. 2002 Nov; 42(14):1549-57.

2. Song M, Kovacevic R. Thermal modelling of friction stir welding in a moving coordinate system and its validation, International Journal Machine Tools Manufacture. 2003 May; 43(6):605-15.

3. Seidel T, Reynolds A. Two-dimensional friction stir welding process model based on fluid mechanics. Science and Technology of Welding and Joining. 2003 May; 8(3):175-83.

4. Colgrove PA, Shercliff HR. Three-dimensional CFD modeling of flow around a threaded friction stir welding tool profile. Journal of Materials Processing Technology. 2005 Nov; 169(2):320-7.

5. Heurtier P, Jones MJ, Desrayaud C, Driver JH, Fontheillet F, Allehaux D. Mechanical and thermal modeling of friction stir welding. Journal of Materials Processing Technology. 2006 Feb; 171(3):348-57.
6. Colgrove PA, Shercliff HR. Experimental and numerical analysis of aluminum alloy 7075-t7351 friction stir welds. Science and Technology of Welding and Joining. 2003 Sep; 08(5):360-8.

7. Hamilton CS, Dymek S, Sommers A. A thermal model of friction stir welding in aluminum alloys. International Journal of Machine Tools and Manufacture. 2008 Aug; 48(10):1120-30.

8. Mijajlovic M, Micic D, Nikolic-Stanojevic V, Milcic M. Numerical simulation of friction stir welding on aluminum alloy 2024-T351 plates. Appl Math Inform and Mech. 2012; 4(2):65-70.

9. Ramanjaneyulu K, Reddy GM, Rao AV, Markandeya R. Structure-property correlation of AA2014 friction stir welds: role of tool pin profile. Jounals of Materials Engineering Performance. 2013 Aug; 22(8):2224-40.

10. Gadakh VS, Adepu K. Heat generation model for taper cylindrical pin profile in FSW. J Mater Res Technology. 2013 Oct-Dec; 02(4):370-5.

11. Heurtier P, Desrayaud C, Montheillet FA. Thermo mechanical analysis of the friction stir welding process. Materials Science Forum Trans Tech. 2002; 396-402:1537-42.

12. Muruganandam D, Raguraman D, Senthilkumar B, Das SL. FSW of aluminium alloys - energy model for taper tool geometry. Elixir Mech Engg. 2013; 65:19864-72.

13. Hajikarimi A, Rahmani K, Farahmand NF. Designing a new model to improve productivity factors implementing the fuzzy goal programming method. Indian Journal of Science and Technology. 2015 May; 8(9):09-12.

14. Mohammadi J, Behnamian Y, Mostafaei A, Gerlich AP. Tool geometry, rotation and travel speeds effects on the properties of dissimilar magnesium/aluminum friction stir welded lap joints. Materials and Design. 2015 Jun; 75(15):95-112. 